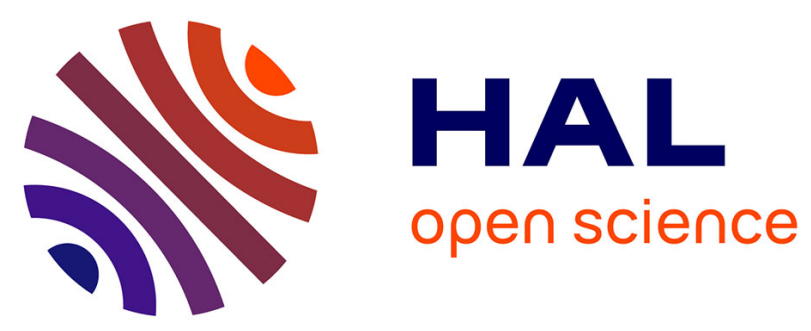

\title{
Dimensioning adaptive optics for future VLTI projects
}

\author{
Fabien Patru, Florentin Millour, Olivier Lai, Marcel Carbillet, Frank \\ Eisenhauer, Stefan Gillessen, Maximilian Haase, Michael Hartl, Frank \\ Haussmann, Jean-Baptiste Le Bouquin, et al.
}

\section{- To cite this version:}

Fabien Patru, Florentin Millour, Olivier Lai, Marcel Carbillet, Frank Eisenhauer, et al.. Dimensioning adaptive optics for future VLTI projects. Adaptive Optics Systems VII, Dec 2020, Online Only, France. pp.286, 10.1117/12.2562433 . hal-03370668

\section{HAL Id: hal-03370668 \\ https://hal.science/hal-03370668}

Submitted on 28 Oct 2021

HAL is a multi-disciplinary open access archive for the deposit and dissemination of scientific research documents, whether they are published or not. The documents may come from teaching and research institutions in France or abroad, or from public or private research centers.
L'archive ouverte pluridisciplinaire HAL, est destinée au dépôt et à la diffusion de documents scientifiques de niveau recherche, publiés ou non, émanant des établissements d'enseignement et de recherche français ou étrangers, des laboratoires publics ou privés. 


\title{
Dimensioning adaptive optics for future VLTI projects
}

\author{
Fabien Patru ${ }^{\mathrm{a}}$, Florentin Millour ${ }^{\mathrm{a}}$, Olivier Lai ${ }^{\mathrm{a}}$, Marcel Carbillet ${ }^{\mathrm{a}}$, Frank Eisenhauer ${ }^{\mathrm{b}}$, Stefan \\ Gillessen $^{\mathrm{b}}$, Maximilian Haase ${ }^{\mathrm{b}}$, Michael Hartl ${ }^{\mathrm{b}}$, Frank Haussmann ${ }^{\mathrm{b}}$, Jean-Baptiste Le \\ Bouquin $^{\mathrm{c}}$, Dieter Lutz ${ }^{\mathrm{b}}$, Christopher Mandla ${ }^{\mathrm{b}}$, Nikhil More ${ }^{\mathrm{b}}$, Thomas Ott ${ }^{\mathrm{b}}$, Thibaut \\ Paumard ${ }^{\mathrm{d}}$, Christian Rau ${ }^{\mathrm{b}}$, Josef Schubert ${ }^{\mathrm{b}}$, Ekkehard Wieprecht ${ }^{\mathrm{b}}$, Julien Woillez ${ }^{\mathrm{e}}$, and Senol \\ Yazici $^{\mathrm{b}}$ \\ ${ }^{a}$ Observatoire de la Côte d'Azur (France) \\ ${ }^{b}$ Max-Planck-Institut für extraterrestrische Physik (Germany) \\ dInstitut de Planétologie et d Astrophysique de Grenoble (France) \\ ${ }^{\mathrm{d}}$ Observatoire de Paris (France) \\ eEuropean Southern Observatory (Germany)
}

\begin{abstract}
The European Southern Observatory offers the opportunity to develop a new generation of instruments for the Very Large Telescope Interferometer. Therefore, it is tempting to upgrade the adaptive optics systems for MACAO on the 8-m unit telescope as well as for NAOMI on the 1.8-m auxiliary telescope. It enables to access to new science cases such as active galactic nuclei with the GRAVITY+ project. Moreover, it would allow to perform at short wavelengths with the IVis proposal. We study here the requirements of such AO upgrade by increasing the number of sub-apertures of the wave-front sensor and the number of actuators of the deformable mirror. We evaluate the needs for a high-Strehl mode in the visible and near infrared wavelengths in various conditions of observation. We present numerical simulations to quantify the performance. We show that a moderate upgrade of NAOMI, and a significant upgrade of MACAO can enable both better dynamic range and sensitivity with the VLTI.
\end{abstract}

Keywords: Adaptive optics, very large telescope interferometer

\section{INTRODUCTION}

The Very Large Telescope Interferometer (VLTI) is today a leading edge facility for long-baseline astrophysics interferometry. With the end of the first generation instruments (AMBER ${ }^{1,2}$ and $\mathrm{MIDI}^{3,4}$ ) and the advent of second generation instruments (GRAVITY ${ }^{5,6}$ and MATISSE ${ }^{7,8}$ ), the facility has reached a level of maturity that allows cutting edge science to be done and images of astrophysical objects to be published as a more common feature.

Yet, the margin for improvements of the VLTI is large. Still just a handful of active galactic nuclei (AGN) can be reached by the VLTI, mainly due today to the limited performances of the adaptive optics (AO). The VLTI is not yet able to make use of its longest baseline $(220 \mathrm{~m})$, being limited by its delay lines length. Finally, the VLTI cannot observe in the shortest wavelengths (V, R, I and J) due to a combination of poor performances of $\mathrm{AO}$ on both $\mathrm{NAOMI}^{9,10}$ on the 1.8-m auxiliary telescopes (AT) and $\mathrm{MACAO}^{11,12}$ on the 8-m unit telescopes (UT), and the decommissioning of the only $\mathrm{J}$ band-sensitive instrument: AMBER.

ESO has issued a call for tenders in 2019 to propose new instruments concepts for the future of the VLTI in the 2030s. Several proposals were presented, but it is notable that most - if not all - of them were proposing

Further author information: (Send correspondence to F. Patru)

F. Patru: E-mail: fabienpatru@gmail.com

F. Millour.: E-mail: s.millour@oca.eu 
upgrades of the VLTI adaptive optics. GRAVITY+ was selected, which contains itself an upgrade of the MACAO adaptive optics of the UTs to reach new heights in sensitivity for AGN characterization at cosmic scales, and improve contrast of exoplanet detection.

Such AO upgrades would enable for instance: $i$. to improve the sensitivity to reach new and fainter objects like merging AGN (e.g. GRAVITY+ project ${ }^{13}$ ); $i$. to improve the high contrast imaging performance to detect exoplanets (e.g. HI-5 proposal $\left.{ }^{14,15}\right)$; iii. to explore interferometry at visible wavelengths - in R-band or I-band - to spatially resolve fundamental stellar physics (e.g. IVis proposal ${ }^{16,17}$ ).

Therefore, we consider useful to revisit the theoretical study of AO performances on the VLTI, great tools to perform such analysis being available today. We present here the results of numerical simulations obtained with the PAOLA software. ${ }^{18}$ We have also compared it with the CAOS software. ${ }^{19}$ Both simulation tools yield rather to similar results with discrepancy of the Strehl of only few percents. We study in particular the requirements for a high-Strehl mode, by increasing the sampling of both the wave-front sensor (WFS) and the deformable mirror (DM). We show that a moderate upgrade of NAOMI, and a significant upgrade of MACAO can enable both better dynamic range and sensitivity with the VLTI.

\section{MAIN PARAMETERS OF THE NUMERICAL SIMULATION}

\begin{tabular}{|c|c|}
\hline Telescope optics parameters & \\
\hline Primary mirror diameter (UT) & $8.0 \mathrm{~m}(\mathrm{MACAO})-1.8 \mathrm{~m}$ (NAOMI) \\
\hline Central obscuration diameter (UT)f & $1.2 \mathrm{~m}(\mathrm{MACAO})-0.138 \mathrm{~m}(\mathrm{NAOMI})$ \\
\hline \multicolumn{2}{|l|}{ Optical turbulence parameters } \\
\hline Seeing angle (at $500 \mathrm{~nm}$ at zenith) & {$[0.6,0.7,0.8,0.9,1.0,1.1,1.2]$ as } \\
\hline Outer scale & $25 \mathrm{~m}$ \\
\hline Airmass (or telescope pointing zenith angle) & $1.5\left(48^{\circ}\right)$ \\
\hline 9 turbulent layers with typical Paranal conditions & Altitude, $\mathrm{Cn}^{2}$, Wind \\
\hline \multicolumn{2}{|l|}{ Scientific instrument parameters } \\
\hline Spectral band of the scientific channel & $\mathrm{R}, \mathrm{J}, \mathrm{H}, \mathrm{K}, \mathrm{L}, \mathrm{M}$ bands \\
\hline Central wavelength of the scientific channel & {$[0.70,1.25,1.65,2.20,3.40,5.00] \mu \mathrm{m}$} \\
\hline Spectral bandwidth of the scientific channel & {$[0.22,0.30,0.35,0.40,0.55,0.30] \mu \mathrm{m}$} \\
\hline \multicolumn{2}{|l|}{ Shack-Hartman wave-front sensor parameters } \\
\hline Spectral band of the sensing channel & R-band \\
\hline Central wavelength of the sensing channel & $0.7 \mu \mathrm{m}$ \\
\hline Spectral bandwidth of the sensing channel & $0.22 \mu \mathrm{m}$ \\
\hline Bolometric magnitude of the on-axis NGS & {$[6,7,8, \ldots, 15,16]$} \\
\hline Pixel read noise of the NGS WFS CCD detector & $0.5 \mathrm{e}-/$ pixel \\
\hline Algorithm for SH-WFS spot centroid calculation & Center-of-gravity mode (CG) \\
\hline Number of pixels across the WFS lenslet width & 8 pixels/lenslet \\
\hline Quantum efficiency of the WFS & 0.65 \\
\hline Total transmission of the system up to the WFS & 0.23 \\
\hline Integration time of the WFS & Optimized $(<10 \mathrm{~ms})$ \\
\hline Number of lenses across the WFS & {$[10 ; 40](\mathrm{MACAO})$} \\
\hline & {$[4 ; 5,6,7,8,9,12](\mathrm{NAOMI})$} \\
\hline \multicolumn{2}{|l|}{ Adaptive optics (AO) \& control loop parameters } \\
\hline Number of actuators across the DM & {$[11 ; 41](\mathrm{MACAO})$} \\
\hline & {$[13 ; 13]$ (NAOMI) } \\
\hline Loop gain & Optimized $(<0.6)$ \\
\hline Servo system time lag (WFS read-out + DM commands) & $0.5 \mathrm{~ms}$ \\
\hline
\end{tabular}

Table 1. Main input parameters of the simulations for UT/MACAO and AT/NAOMI. 
The main input parameters of the numerical simulations are given in table 1 . We study the expected performance (e.g. Strehl ratio) while correcting in R-band on the sensing channel and observing in another band ( R, J, H, K, L, M bands) on the scientific channel. We mainly evaluate the requested number of subapertures of the WFS and the number of actuators of the DM as a function of the atmospheric conditions (seeing), the wavelength of observation and the natural guide star (NGS) magnitude. The current UT/MACAO system has 10x10 equivalent (curvature) WFS subaperture and about 11x11 DM actuators. The MACAO upgrade foreseen for the GRAVITY+ project will have 40x40 WFS subaperture and 41x41 DM actuators. The current AT/NAOMI system has 4x4 WFS subapertures and 13x13 DM actuators. A NAOMI upgrade would need more WFS subapertures (typically 8x8) while keeping the same number of DM actuators.

We consider a Shack-Hartman WFS having 0.5 e-/pixel read noise, a $6 \times 6$ pixel subaperture and a centerof-gravity mode for the spot centroid calculation. The read-out noise and the quantum efficiency of the WFS detector are chosen according to the specifications of the $\mathrm{Ocam}^{2}$ manufactured by First Light Imaging: read-out noise $<1$ electron ; quantum efficiency of $95 \%$ pic, and of $65 \%$ in the near-infrared at $900 \mathrm{~nm}$. The servo-lag time is set to $0.5 \mathrm{~ms}$, including the WFS integration time, the command computation time and the update of the DM. The WFS integration time and the loop gain are optimized both at a time for each setup so as to minimize the variance of the residual wavefront spectrum. Such optimization is needed especially for faint NGS stars.

The total transmission from the telescope primary mirror up to the WFS is computed as follows:

- Transmission after M8 (i.e. the MACAO DM) $=64 \%$.

- Transmission of M9 dichroic in the optical (450 to $900 \mathrm{~nm})=90 \%$.

- Typical reflectivity of $95 \%$ for each optic in the WFS (membrane mirror, SBM1, SBM2, SBM3, SBM4, K-mirror surface 1, 2 and 3).

- Transmission of the lenslet array of the Shack-hartmann. Lenslets are square ones, thus the expected transmission is about $95 \%$.

- Quantum efficiency $=65 \%$ at $900 \mathrm{~nm}$, assuming the same value at $700 \mathrm{~nm}$ in R-band.

- Total transmission $=0.64 * 0.90 * 0.95^{8 *} 0.95^{*} 0.65=0.236$.

- Total transmission $=23 \%$.

If the sensor and the detector are both in the same R-band, the transmission is divided by a factor of 2 , assuming a dichroic 50/50 for separating the light in between the sensing arm and the scientific arm.

\section{RESULTS OF THE NUMERICAL SIMULATION}

We show the point spread function obtained with UT/MACAO and with AT/NAOMI in the visible or infrared wavelengths in their current setup and once upgraded (Fig. 1). It appears clearly that such AO upgrade can provide more contrasted images. The dynamic range is strongly improved especially in the visible wavelengths.

Next, for both UT/MACAO and AT/NAOMI, we plot the on-axis Strehl ratio as a function of the guide star magnitude for different numbers of WFS subapertures and DM actuators ( $4 \times 4$ up to 40x40), for various conditions of turbulence (seeing from 0.6 to 1.2 ) and for different spectral bands of observation (R, J, H, K, L, $\mathrm{M}$ bands) while correcting in R-band (Fig. 2, 3, 4,5). The criteria used here for choosing the optimum setup is to provide a Strehl ratio above $20 \%$ while maximizing the NGS magnitude.

\subsection{UT/MACAO upgrade}

With the current MACAO made of 10x10 WFS sub-apertures, a Strehl ratio of $20 \%$ is reached at 0.8 as seeing for a NGS magnitude up to 17 in K-band whereas it remains very low in R-band. With the MACAO upgrade made of 40x40 WFS sub-apertures, a Strehl ratio of $20 \%$ is reached at 0.8 as seeing for a NGS magnitude up to 9.5 in R-band and up to 13.5 in K-band. Such upgrade gives access to the visible wavelengths at the cost of a lower magnitude limit in the infrared wavelengths. For bright targets and 0.8 as seeing, the Strehl is improved from $15 \%$ to $55 \%$ in R-band and from $82 \%$ to $95 \%$ in K-band (Fig. 2 and 3). 


\subsection{AT/NAOMI upgrade}

With the current NAOMI made of $4 \mathrm{x} 4$ WFS sub-apertures, a Strehl ratio of $20 \%$ is reached at 0.8 as seeing for a NGS magnitude up to 16 in K-band whereas it remains below $20 \%$ in R-band. For upgrading NAOMI, we suggest 8x8 WFS sub-apertures with the current 13x13 DM actuators. Such upgrade enables to reach a Strehl ratio of $20 \%$ at 0.8 as seeing with a NGS magnitude up to 10.5 in R-band and up to 14.5 in K-band. It enables also to observe in the visible wavelengths. For bright targets and 0.8 as seeing, the Strehl is improved from $2 \%$ to $55 \%$ in R-band and from $60 \%$ to $95 \%$ in K-band (Fig. 4 and 5).
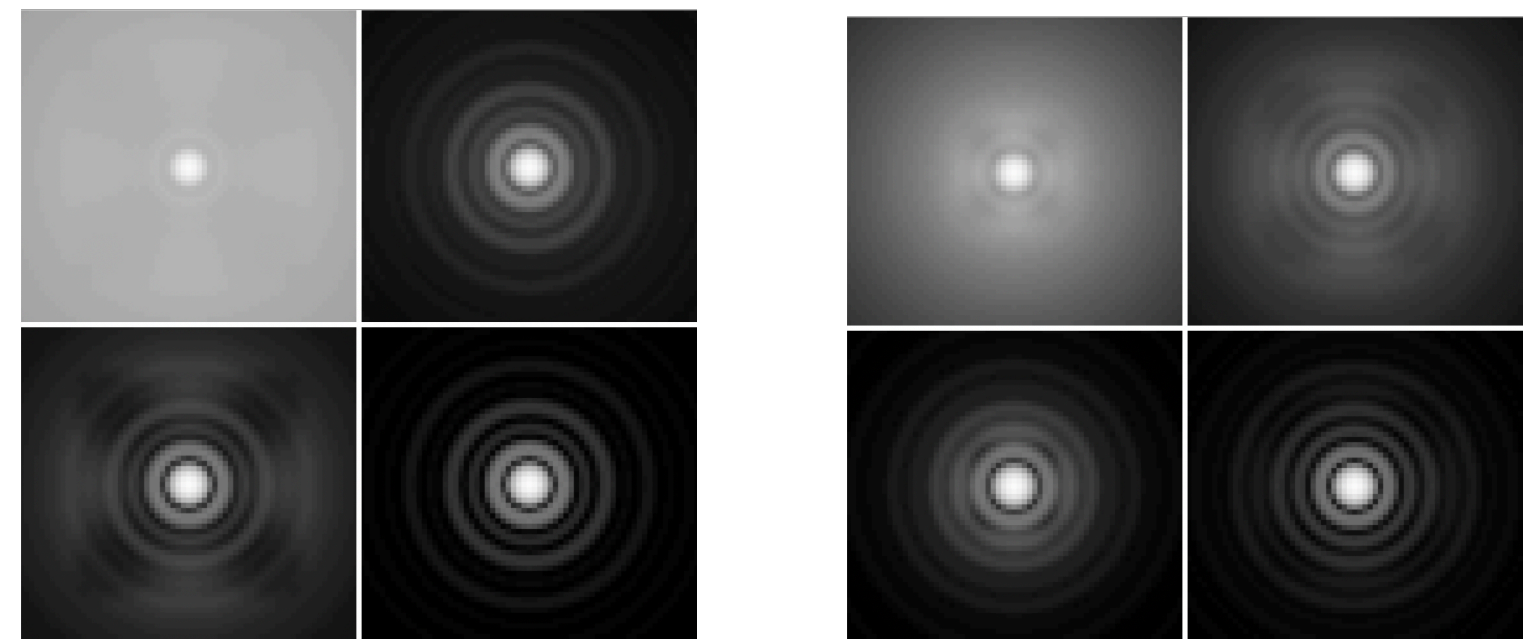

Figure 1. Figure on the left: Point spread function obtained with UT/MACAO in its current version with 10x10 WFS subapertures (left) and in its upgraded version with 40x40 WFS subapertures (right). Central wavelength of $0.7 \mu \mathrm{m}$ (top) and $2.2 \mu \mathrm{m}$ (bottom). Seeing of 0.8 as. NGS magnitude of 8 . Figure on the right: Point spread function obtained with AT/NAOMI in its current version with 4x4 WFS subapertures (left) and in an upgraded version with $8 \mathrm{x} 8$ WFS subapertures (right). Central wavelength of $0.7 \mu \mathrm{m}$ (top) and $2.2 \mu \mathrm{m}$ (bottom). Seeing of 0.8 as. NGS magnitude of 8 .
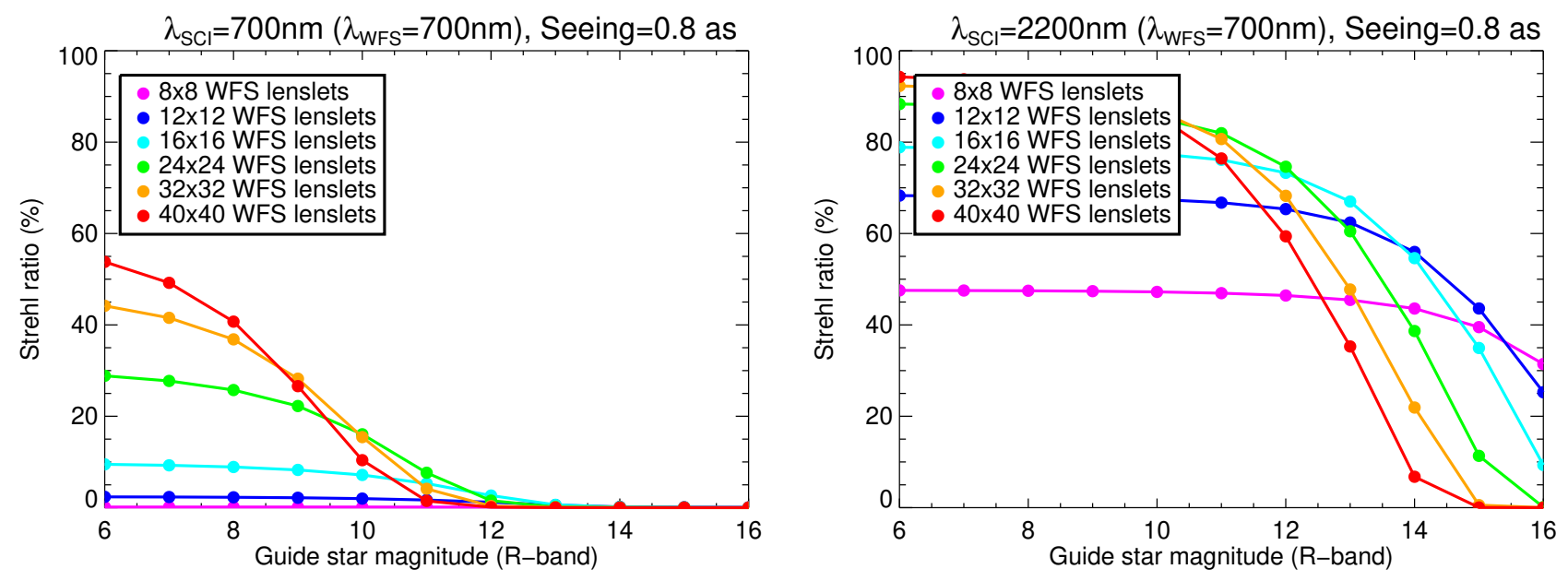

Figure 2. Strehl as a function of the guide star magnitude with UT/MACAO for different numbers of WFS subapertures in R-band (left) and in K-band (right). Strehl of 0.8 as. 

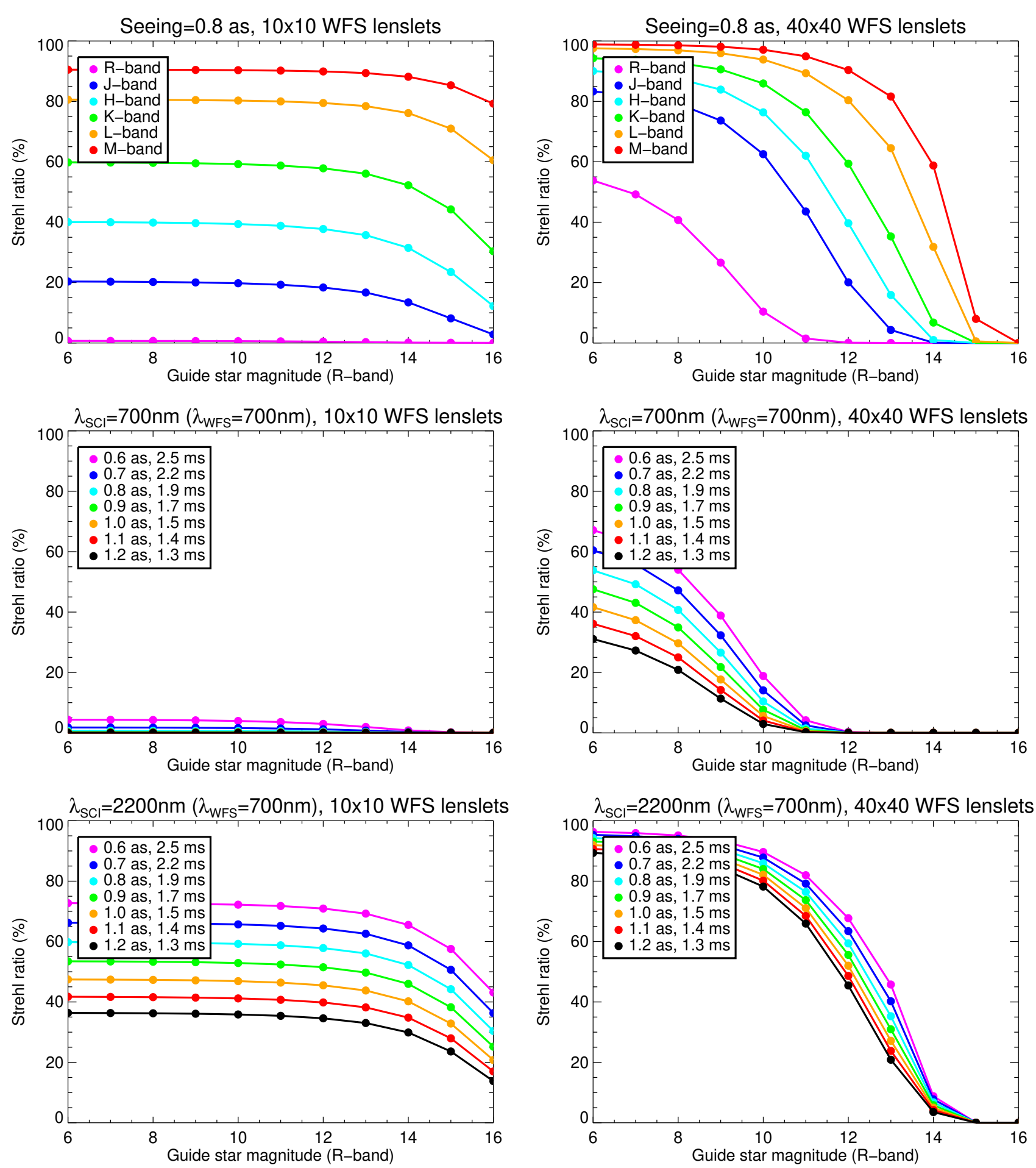

Figure 3. Strehl as a function of the guide star magnitude with UT/MACAO in its current version using 10x10 WFS subapertures (left) and in its upgraded version using 40x40 WFS subapertures (right). Strehl curves for different wavelengths of observation and a Strehl of 0.8 as (top). Strehl curves for different conditions of turbulence in R-band (middle) and in K-band (bottom). 

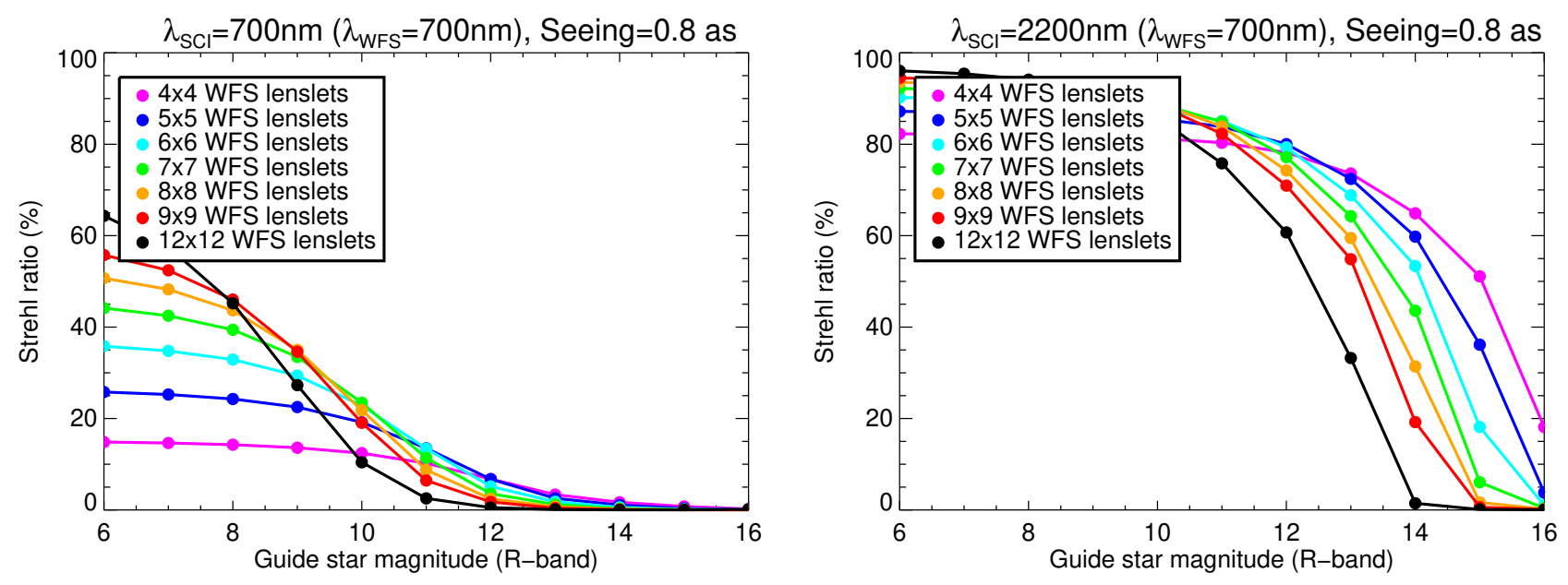

Figure 4. Strehl as a function of the guide star magnitude with AT/NAOMI for different numbers of WFS subapertures in R-band (left) and in K-band (right). Strehl of 0.8 as.

\section{CONCLUSION}

We have shown by numerical computation that a moderate upgrade of NAOMI, and a significant upgrade of MACAO can enable both better dynamic range and sensitivity with the VLTI. At high flux (if photon noiselimited), fitting error and aliasing error dominate. For compensating that, we can: $i$. increase the number of DM actuators to reduce the fitting error; $i$. increase the number of WFS subapertures to reduce the aliasing error; iii. optimize the WFS integration time and the loop gain. At low flux (if read-out noise-limited), WFS noise error and servo-lag error dominate. For improving that, we can: $i$. increase the subaperture size but decrease the subaperture number, so as to optimize the flux per WFS subaperture; $i i$. decrease the read-out noise with a new detector; iii. increase the WFS integration time.

Further, the performance can be improved in the case of faint NGS by increasing the NGS WFS bandwidth. Here the bandwidth is set to $220 \mathrm{~nm}$ (R-band only). A bandwidth of $300 \mathrm{~nm}$ improves the performance limit by about one magnitude. A good option would be to use a WFS covering not only the R-band but also the V-band.

\section{ACKNOWLEDGMENTS}

The first author would like to thank OPTICON (Optical Infrared Coordination Network for Astronomy) for funding his research job at Côte d'Azur Observatory in Nice. OPTICON (https://www.astro-opticon.org) is a European Council (EC) funded coordination network which leads to coordinated instrument development, future planning, and builds the key consortia of institutes. The study presented here is part of the work-package WP8 (JRA8) - led by Jörg-Uwe Pott in MPIA (jpott@mpia.de) - for studying the Next Generation Instrument Concepts for VLT Interferometry (VLTI). This JRA aims at enhancing the existing VLTI facility by providing concrete concepts and feasibility studies for future interferometric instrumentation.

\section{REFERENCES}

[1] Petrov, R. G., Malbet, F., Weigelt, G., Antonelli, P., Beckmann, U., Bresson, Y., Chelli, A., Dugué, M., Duvert, G., Gennari, S., Glück, L., Kern, P., Lagarde, S., Le Coarer, E., Lisi, F., Millour, F., Perraut, K., Puget, P., Rantakyrö, F., Robbe-Dubois, S., Roussel, A., Salinari, P., Tatulli, E., Zins, G., Accardo, M., Acke, B., Agabi, K., Altariba, E., Arezki, B., Aristidi, E., Baffa, C., Behrend, J., Blöcker, T., Bonhomme, S., Busoni, S., Cassaing, F., Clausse, J.-M., Colin, J., Connot, C., Delboulbé, A., Domiciano de Souza, A., Driebe, T., Feautrier, P., Ferruzzi, D., Forveille, T., Fossat, E., Foy, R., Fraix-Burnet, D., Gallardo, A., Giani, E., Gil, C., Glentzlin, A., Heiden, M., Heininger, M., Hernandez Utrera, O., Hofmann, K.-H., Kamm, D., Kiekebusch, M., Kraus, S., Le Contel, D., Le Contel, J.-M., Lesourd, T., Lopez, B., Lopez, M., Magnard, Y., Marconi, A., Mars, G., Martinot-Lagarde, G., Mathias, P., Mège, P., Monin, J.-L., Mouillet, 
Seeing $=0.8$ as, $4 \times 4$ WFS lenslets
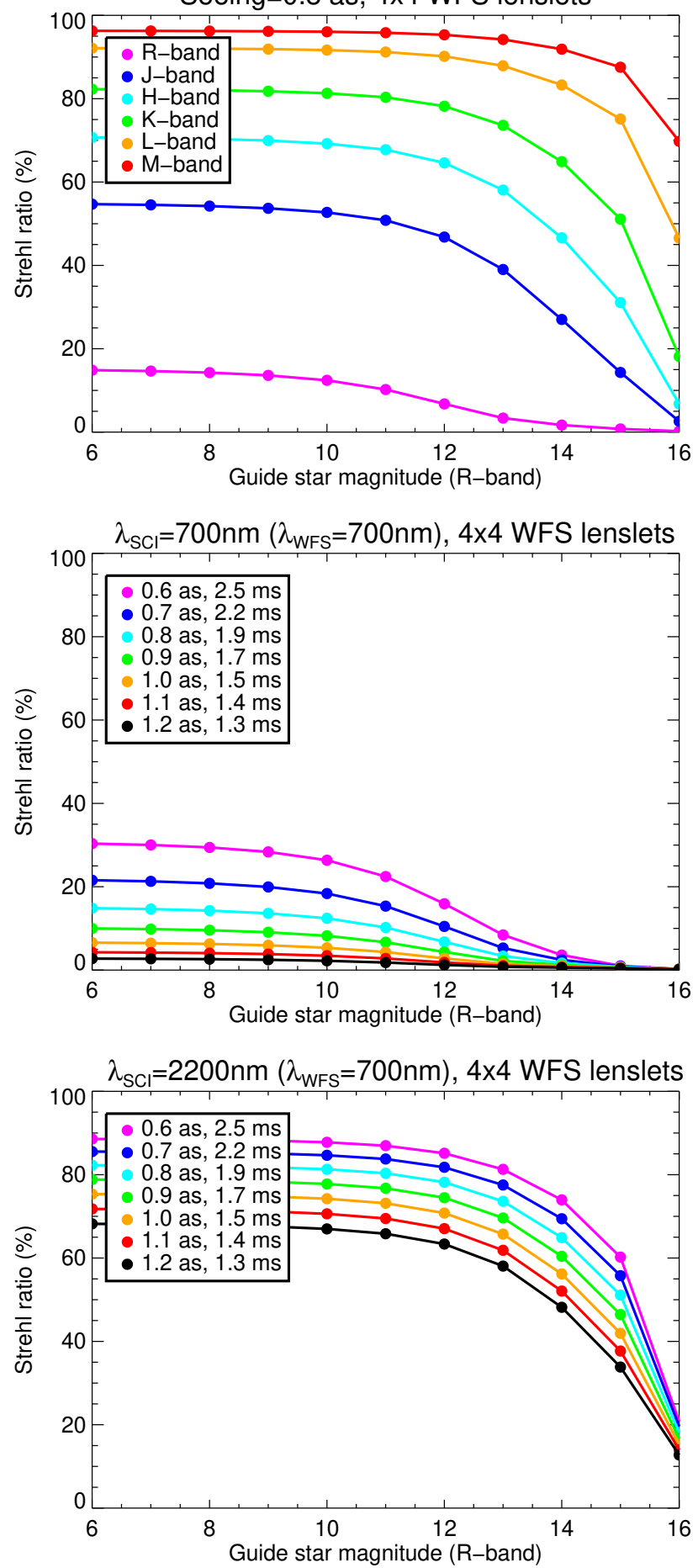

Seeing $=0.8$ as, $8 \times 8$ WFS lenslets
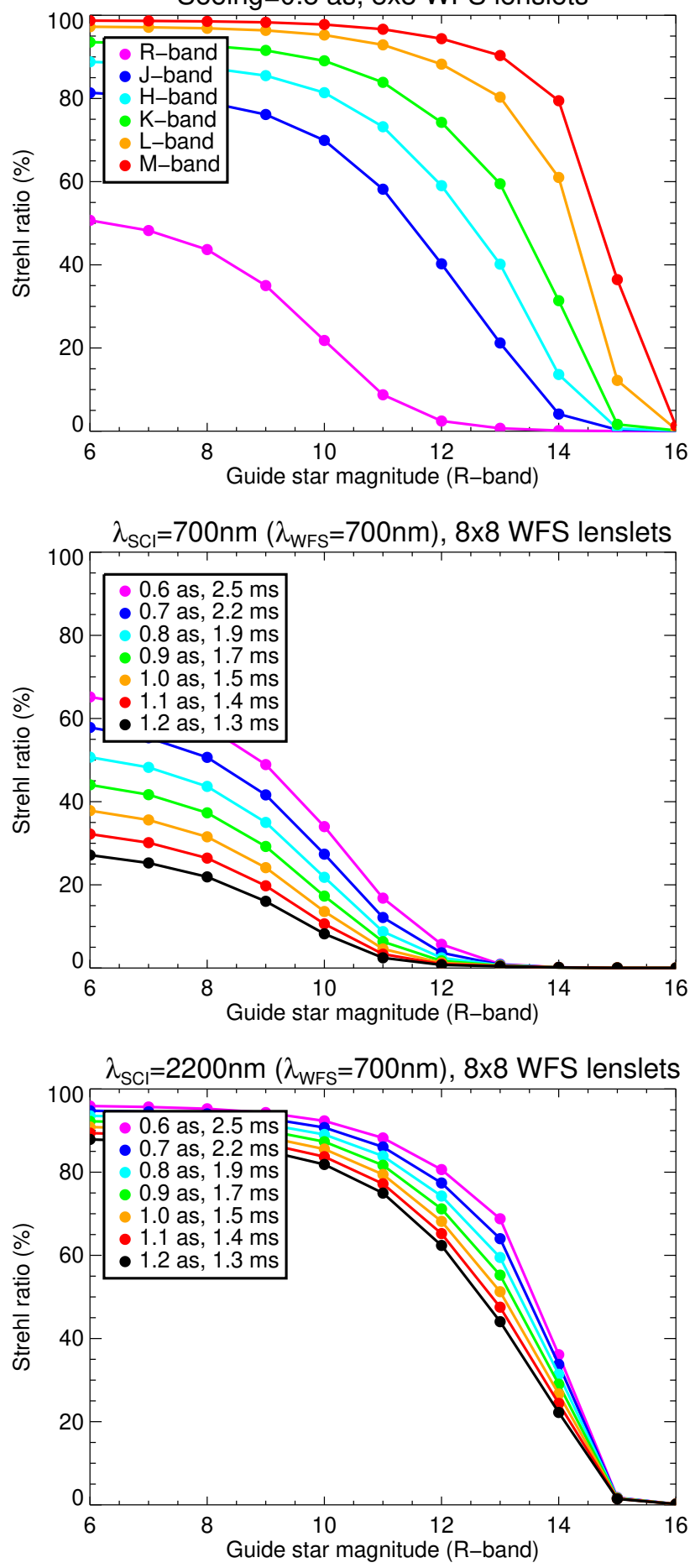

Figure 5. Strehl as a function of the guide star magnitude with AT/NAOMI in its current version using 4x4 WFS subapertures (left) and in an upgraded version using 8x8 WFS subapertures (right). Strehl curves for different wavelengths of observation and a Strehl of 0.8 as (top). Strehl curves for different conditions of turbulence in R-band (middle) and in K-band (bottom). 
D., Mourard, D., Nussbaum, E., Ohnaka, K., Pacheco, J., Perrier, C., Rabbia, Y., Rebattu, S., Reynaud, F., Richichi, A., Robini, A., Sacchettini, M., Schertl, D., Schöller, M., Solscheid, W., Spang, A., Stee, P., Stefanini, P., Tallon, M., Tallon-Bosc, I., Tasso, D., Testi, L., Vakili, F., von der Lühe, O., Valtier, J.-C., Vannier, M., and Ventura, N., "AMBER, the near-infrared spectro-interferometric three-telescope VLTI instrument," Astronomy and Astrophysics 464, 1-12 (2007).

[2] Mérand, A., Stefl, S., Bourget, P., Ramirez, A., Patru, F., Haguenauer, P., and Brillant, S., "Perspectives for the AMBER Beam Combiner," in [Society of Photo-Optical Instrumentation Engineers (SPIE) Conference Series], Proc. SPIE $\mathbf{7 7 3 4}$ (2010).

[3] Leinert, C., Graser, U., Przygodda, F., Waters, L. B. F. M., Perrin, G., Jaffe, W., Lopez, B., Bakker, E. J., Böhm, A., Chesneau, O., Cotton, W. D., Damstra, S., de Jong, J., Glazenborg-Kluttig, A. W., Grimm, B., Hanenburg, H., Laun, W., Lenzen, R., Ligori, S., Mathar, R. J., Meisner, J., Morel, S., Morr, W., Neumann, U., Pel, J. W., Schuller, P., Rohloff, R. R., Stecklum, B., Storz, C., von der Lühe, O., and Wagner, K., "MIDI - the 10 um instrument on the VLTI," Astrophysics and Space Science 286, 73-83 (Jan. 2003).

[4] Leinert, C., Graser, U., Richichi, A., Schöller, M., Waters, L. F. B. M., Perrin, G., Jaffe, W., Lopez, B., Glazenborg-Kluttig, A., Przygodda, F., Morel, S., Biereichel, P., Haddad, N., Housen, N., and Wallander, A., "MIDI combines light from the VLTI: the start of $10 \mu \mathrm{m}$ interferometry at ESO," The Messenger 112, 13-18 (June 2003).

[5] Eisenhauer, F., Perrin, G., Brandner, W., Straubmeier, C., Richichi, A., Gillessen, S., Berger, J. P., Hippler, S., Eckart, A., Schöller, M., Rabien, S., Cassaing, F., Lenzen, R., Thiel, M., Clénet, Y., Ramos, J. R., Kellner, S., Fédou, P., Baumeister, H., Hofmann, R., Gendron, E., Boehm, A., Bartko, H., Haubois, X., Klein, R., Dodds-Eden, K., Houairi, K., Hormuth, F., Gräter, A., Jocou, L., Naranjo, V., Genzel, R., Kervella, P., Henning, T., Hamaus, N., Lacour, S., Neumann, U., Haug, M., Malbet, F., Laun, W., Kolmeder, J., Paumard, T., Rohloff, R. R., Pfuhl, O., Perraut, K., Ziegleder, J., Rouan, D., and Rousset, G., "GRAVITY: getting to the event horizon of Sgr A*," in [Optical and Infrared Interferometry], Schöller, M., Danchi, W. C., and Delplancke, F., eds., Society of Photo-Optical Instrumentation Engineers (SPIE) Conference Series 7013, 70132A (July 2008).

[6] Eisenhauer, F., Perrin, G., Brandner, W., Straubmeier, C., Perraut, K., Amorim, A., Schöller, M., Gillessen, S., Kervella, P., Benisty, M., Araujo-Hauck, C., Jocou, L., Lima, J., Jakob, G., Haug, M., Clénet, Y., Henning, T., Eckart, A., Berger, J. P., Garcia, P., Abuter, R., Kellner, S., Paumard, T., Hippler, S., Fischer, S., Moulin, T., Villate, J., Avila, G., Gräter, A., Lacour, S., Huber, A., Wiest, M., Nolot, A., Carvas, P., Dorn, R., Pfuhl, O., Gendron, E., Kendrew, S., Yazici, S., Anton, S., Jung, Y., Thiel, M., Choquet, É., Klein, R., Teixeira, P., Gitton, P., Moch, D., Vincent, F., Kudryavtseva, N., Ströbele, S., Sturm, S., Fédou, P., Lenzen, R., Jolley, P., Kister, C., Lapeyrère, V., Naranjo, V., Lucuix, C., Hofmann, R., Chapron, F., Neumann, U., Mehrgan, L., Hans, O., Rousset, G., Ramos, J., Suarez, M., Lederer, R., Reess, J. M., Rohloff, R. R., Haguenauer, P., Bartko, H., Sevin, A., Wagner, K., Lizon, J. L., Rabien, S., Collin, C., Finger, G., Davies, R., Rouan, D., Wittkowski, M., Dodds-Eden, K., Ziegler, D., Cassaing, F., Bonnet, H., Casali, M., Genzel, R., and Lena, P., "GRAVITY: Observing the Universe in Motion," The Messenger 143, 16-24 (Mar. 2011).

[7] Lopez, B., Wolf, S., Lagarde, S., Abraham, P., Antonelli, P., Augereau, J. C., Beckman, U., Behrend, J., Berruyer, N., Bresson, Y., Chesneau, O., Clausse, J. M., Connot, C., Demyk, K., Danchi, W. C., Dugué, M., Flament, S., Glazenborg, A., Graser, U., Henning, T., Hofmann, K. H., Heininger, M., Hugues, Y., Jaffe, W., Jankov, S., Kraus, S., Laun, W., Leinert, C., Linz, H., Mathias, P., Meisenheimer, K., Matter, A., Menut, J. L., Millour, F., Neumann, U., Nussbaum, E., Niedzielski, A., Mosonic, L., Petrov, R., Ratzka, T., Robbe-Dubois, S., Roussel, A., Schertl, D., Schmider, F. X., Stecklum, B., Thiebaut, E., Vakili, F., Wagner, K., Waters, L. B. F. M., and Weigelt, G., "MATISSE: perspective of imaging in the mid-infrared at the VLTI," in [Society of Photo-Optical Instrumentation Engineers (SPIE) Conference Series], Monnier, J. D., Schöller, M., and Danchi, W. C., eds., Society of Photo-Optical Instrumentation Engineers (SPIE) Conference Series 6268, 62680Z (June 2006).

[8] Lopez, B., Lagarde, S., Jaffe, W., Petrov, R., Schöller, M., Antonelli, P., Beckmann, U., Berio, P., Bettonvil, F., Glindemann, A., Gonzalez, J. C., Graser, U., Hofmann, K. H., Millour, F., Robbe-Dubois, S., Venema, L., Wolf, S., Henning, T., Lanz, T., Weigelt, G., Agocs, T., Bailet, C., Bresson, Y., Bristow, P., Dugué, M., Heininger, M., Kroes, G., Laun, W., Lehmitz, M., Neumann, U., Augereau, J. C., Avila, G., Behrend, J., 
van Belle, G., Berger, J. P., van Boekel, R., Bonhomme, S., Bourget, P., Brast, R., Clausse, J. M., Connot, C., Conzelmann, R., Cruzalèbes, P., Csepany, G., Danchi, W., Delbo, M., Delplancke, F., Dominik, C., van Duin, A., Elswijk, E., Fantei, Y., Finger, G., Gabasch, A., Gay, J., Girard, P., Girault, V., Gitton, P., Glazenborg, A., Gonté, F., Guitton, F., Guniat, S., De Haan, M., Haguenauer, P., Hanenburg, H., Hogerheijde, M., ter Horst, R., Hron, J., Hugues, Y., Hummel, C., Idserda, J., Ives, D., Jakob, G., Jasko, A., Jolley, P., Kiraly, S., Köhler, R., Kragt, J., Kroener, T., Kuindersma, S., Labadie, L., Leinert, C., Le Poole, R., Lizon, J. L., Lucuix, C., Marcotto, A., Martinache, F., Martinot-Lagarde, G., Mathar, R., Matter, A., Mauclert, N., Mehrgan, L., Meilland, A., Meisenheimer, K., Meisner, J., Mellein, M., Menardi, S., Menut, J. L., Merand, A., Morel, S., Mosoni, L., Navarro, R., Nussbaum, E., Ottogalli, S., Palsa, R., Panduro, J., Pantin, E., Parra, T., Percheron, I., Duc, T. P., Pott, J. U., Pozna, E., Przygodda, F., Rabbia, Y., Richichi, A., Rigal, F., Roelfsema, R., Rupprecht, G., Schertl, D., Schmidt, C., Schuhler, N., Schuil, M., Spang, A., Stegmeier, J., Thiam, L., Tromp, N., Vakili, F., Vannier, M., Wagner, K., and Woillez, J., "An Overview of the MATISSE Instrument — Science, Concept and Current Status," The Messenger 157, 5-12 (Sept. 2014).

[9] Dorn, R. J., Aller-Carpentier, E., Andolfato, L., Berger, J. P., Delplancke-Ströbele, F., Dupuy, C., Fedrigo, E., Gitton, P., Hubin, N., Le Louarn, M., Lilley, P., Jolley, P., Marchetti, E., Mclay, S., Paufique, J., Pasquini, L., Quentin, J., Rakich, A., Ridings, R., Reyes, J., Schmid, C., Suarez, M., Phan, D. T., and Woillez, J., "NAOMI - A New Adaptive Optics Module for Interferometry," The Messenger 156, 12-15 (June 2014).

[10] Woillez, J., Abad, J. A., Abuter, R., Aller Carpentier, E., Alonso, J., Andolfato, L., Barriga, P., Berger, J. P., Beuzit, J. L., Bonnet, H., Bourdarot, G., Bourget, P., Brast, R., Caniguante, L., Cottalorda, E., Darré, P., Delabre, B., Delboulbé, A., Delplancke-Ströbele, F., Dembet, R., Donaldson, R., Dorn, R., Dupeyron, J., Dupuy, C., Egner, S., Eisenhauer, F., Fischer, G., Frank, C., Fuenteseca, E., Gitton, P., Gonté, F., Guerlet, T., Guieu, S., Gutierrez, P., Haguenauer, P., Haimerl, A., Haubois, X., Heritier, C., Huber, S., Hubin, N., Jolley, P., Jocou, L., Kirchbauer, J. P., Kolb, J., Kosmalski, J., Krempl, P., Le Bouquin, J. B., Le Louarn, M., Lilley, P., Lopez, B., Magnard, Y., Mclay, S., Meilland, A., Meister, A., Merand, A., Moulin, T., Pasquini, L., Paufique, J., Percheron, I., Pettazzi, L., Pfuhl, O., Phan, D., Pirani, W., Quentin, J., Rakich, A., Ridings, R., Riedel, M., Reyes, J., Rochat, S., Santos Tomás, G., Schmid, C., Schuhler, N., Shchekaturov, P., Seidel, M., Soenke, C., Stadler, E., Stephan, C., Suárez, M., Todorovic, M., Valdes, G., Verinaud, C., Zins, G., and Zúñiga-Fernández, S., "NAOMI: the adaptive optics system of the Auxiliary Telescopes of the VLTI," Astronomy and Astrophysics 629, A41 (Sept. 2019).

[11] Arsenault, R., Alonso, J., Bonnet, H., Brynnel, J., Delabre, B., Donaldson, R., Dupuy, C., Fedrigo, E., Spyromilio, J., Erm, T., Farinato, J., Hubin, N., Ivanescu, L., Kasper, M., Oberti, S., Paufique, J., Rossi, S., Tordo, S., Stroebele, S., Lizon, J. L., Gigan, P., Pouplard, F., Delplancke, F., Silber, A., Quattri, M., and Reiss, R., "MACAO-VLTI first light: adaptive optics at the service of interferometry," The Messenger 112, 7-12 (June 2003).

[12] Arsenault, R., Alonso, J., Bonnet, H., Brynnel, J., Delabre, B., Donaldson, R., Dupuy, C., Fedrigo, E., Farinato, J., Hubin, N. N., Ivanescu, L., Kasper, M. E., Paufique, J., Rossi, S., Tordo, S., Stroebele, S., Lizon, J.-L., Gigan, P., Delplancke, F., Silber, A., Quattri, M., and Reiss, R., "MACAO-VLTI: An Adaptive Optics system for the ESO VLT interferometer," in [Adaptive Optical System Technologies II], Wizinowich, P. L. and Bonaccini, D., eds., Society of Photo-Optical Instrumentation Engineers (SPIE) Conference Series 4839, 174-185 (Feb. 2003).

[13] Eisenhauer, F., "GRAVITY+: Towards faint science," in [The Very Large Telescope in 2030], 30 (July 2019).

[14] Defrère, D., Absil, O., Berger, J. P., Boulet, T., Danchi, W. C., Ertel, S., Gallenne, A., Hénault, F., Hinz, P., Huby, E., Ireland, M., Kraus, S., Labadie, L., Le Bouquin, J. B., Martin, G., Matter, A., Mérand, A., Mennesson, B., Minardi, S., Monnier, J. D., Norris, B., Orban de Xivry, G., Pedretti, E., Pott, J. U., Reggiani, M., Serabyn, E., Surdej, J., Tristram, K. R. W., and Woillez, J., "The path towards high-contrast imaging with the VLTI: the Hi-5 project," Experimental Astronomy 46, 475-495 (Dec. 2018).

[15] Defrère, D., Ireland, M., Absil, O., Berger, J. P., Danchi, W. C., Ertel, S., Gallenne, A., Hénault, F., Hinz, P., Huby, E., Kraus, S., Labadie, L., Le Bouquin, J. B., Martin, G., Matter, A., Mennesson, B., Mérand, A., Minardi, S., Monnier, J. D., Norris, B., Orban de Xivry, G., Pedretti, E., Pott, J. U., Reggiani, M., 
Serabyn, E., Surdej, J., Tristram, K. R. W., and Woillez, J., "Hi-5: a potential high-contrast thermal nearinfrared imager for the VLTI," in [Optical and Infrared Interferometry and Imaging VI], Creech-Eakman, M. J., Tuthill, P. G., and Mérand, A., eds., Society of Photo-Optical Instrumentation Engineers (SPIE) Conference Series 10701, 107010U (July 2018).

[16] Millour, F., Mourard, D., Woillez, J., Berio, P., Chiavassa, A., Creevey, O., Lagadec, E., Martinod, M.-A., Meilland, A., Nardetto, N., Perraut, K., and Stee, P., "Perspectives of a visible instrument on the VLTI," Experimental Astronomy 46, 497-509 (Dec. 2018).

[17] Millour, F., "A visible addition to the VLTI," in [The Very Large Telescope in 2030], 32 (July 2019).

[18] Jolissaint, L., "Synthetic modeling of astronomical closed loop adaptive optics," Journal of the European Optical Society - Rapid publications, 5, 100555 (2010).

[19] Carbillet, M., Vérinaud, C., Femenía, B., Riccardi, A., and Fini, L., "Modelling astronomical adaptive optics - I. The software package CAOS," Monthly Notices of the Royal Astronomical Society 356, $1263-1275$ (Feb. 2005). 